Article

\title{
Synthesis and Magnetic Properties of Stable Radical Derivatives Carrying a Phenylacetylene Unit
}

\author{
Shogo Miyashiro, Tomoaki Ishii, Youhei Miura and Naoki Yoshioka * (1) \\ Department of Applied Chemistry, Faculty of Science and Technology, Keio University, Yokohama 223-8522, \\ Japan; jiro38460506@gmail.com (S.M.); tomoaki3272@gmail.com (T.I.); y-miura@applc.keio.ac.jp (Y.M.) \\ * Correspondence: yoshioka@applc.keio.ac.jp; Tel.: +81-45-566-1585
}

Received: 6 January 2018; Accepted: 7 February 2018; Published: 9 February 2018

\begin{abstract}
A nitronyl nitroxide derivative, 2-phenylethynyl-4,4,5,5-tetramethyl-4,5-dihydro- $1 \mathrm{H}$ imidazol-1-oxyl-3-oxide (1), and two verdazyl derivatives carrying a phenylacetylene unit, 1,5-diphenyl-3-phenylethynyl-6-oxo-1,2,4,5-tetrazin-2-yl (2) and 1,5-diisopropyl-3-phenylethynyl6-oxo-1,2,4,5-tetrazin-2-yl (3), were synthesized and their packing structures were studied by X-ray crystallographic analysis and magnetically characterized in the solid state. While $\mathbf{1}$ and $\mathbf{3}$ had an isolated doublet spin state, 2 formed an antiferromagnetically coupled pair $\left(2 J / k_{\mathrm{B}}=-118 \mathrm{~K}\right)$. Density functional theory (DFT) calculations reveal that the spin density polarized in the phenyl group decreases as the dihedral angle between the phenyl ring and radical plane increases.
\end{abstract}

Keywords: stable radical; phenylacetylene; nitronyl nitroxide; verdazyl; magnetic property; computational analysis

\section{Introduction}

The study of stable organic radicals has attracted a great deal of attention because of their wide applicability for spin probes, molecule-based magnets, and molecular conductors [1-8]. To assess the magnetic properties of organic radical solids, it is important to investigate the correlation between molecular arrangement and magnetic properties based on crystal engineering strategies [9-27]. For the purpose of inducing the formation of magnetic molecular self-assemblies, van der Waals interactions [9,10,12-14,18], hydrogen bonds [16,17,19-23,25,26], and aromatic stackings $[11,15,24,27]$ have been introduced to various stable radical derivatives such as phenoxyl, nitroxyl, etc. and their effects have been examined. As for verdazyl radical derivatives, strong intermolecular magnetic interactions induced by aromatic stackings have been reported [28-35]. In addition to the control of intermolecular interactions, introduction of specific substituents is also a useful tool for design of molecular packing. The ethynyl group has a rigid linker, and it can also propagate magnetic interaction through the conjugate system and freely rotate around the bond. In the field of crystal engineering, the free rotation of ethynyl group is widely used for the construction of a supramolecular architecture [36,37]. Although the synthetic study [38-42] and computational study [43-45] of ethynyl-substituted derivatives were reported, a limited number of papers have discussed their magneto-structural correlation [33,34,42]. We synthesized three derivatives, 2-phenylethynyl-4,4,5,5-tetramethyl-4,5-dihydro- $H$-imidazol-1-oxyl-3-oxide (1), 1,5-diphenyl-3-phenylethynyl-6-oxo-1,2,4,5-tetrazin-2-yl (2), and 1,5-diisopropyl-3-phenylethynyl6-oxo-1,2,4,5-tetrazin-2-yl (3) (Chart 1). While the synthesis of 1 has already been reported [38], structural analysis and solid-state magnetic characterization were not conducted. In this paper, we described the crystal structures and magnetic properties of 1,2 and 3 . To elucidate the effect of a directly substituted ethynyl group, the spin densities of 1, 2 and 3 were estimated using a computational method. 


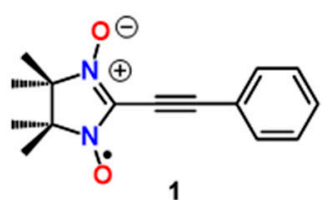

1
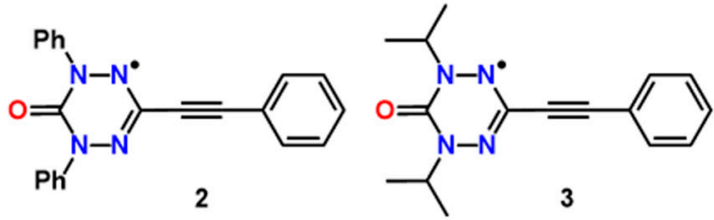

Chart 1. The chemical structures of 1, 2 and 3.

\section{Results}

\subsection{Synthesis and Electron Paramagnetic Resonance Spectra}

The syntheses of compounds 1-3 are summarized in Scheme 1. Typically, 2,3-bis(hydroxyamino)2,3-dimethylbutane sulfate reacts with an aldehyde and the precursor of nitronyl nitroxide (NN) is obtained, but this method did not lead to $\mathbf{1}$ due to the reaction between ethynyl and the hydroxy group [40]. Therefore, the synthesis route of $\mathbf{1}$ was basically followed by Ullman's route through alkene and dehydrobromide compounds [38]. To obtain the verdazyl (VZ) derivatives 2 and 3, the hydrazine derivatives protected by Boc, 8 and 10 [46-48] were synthesized from 6 [49] and 9 [50], respectively. They were combined with the aldehyde derivative [51,52] and 2 and $\mathbf{3}$ were synthesized by the oxidation of 11 and $\mathbf{1 2}$, respectively.
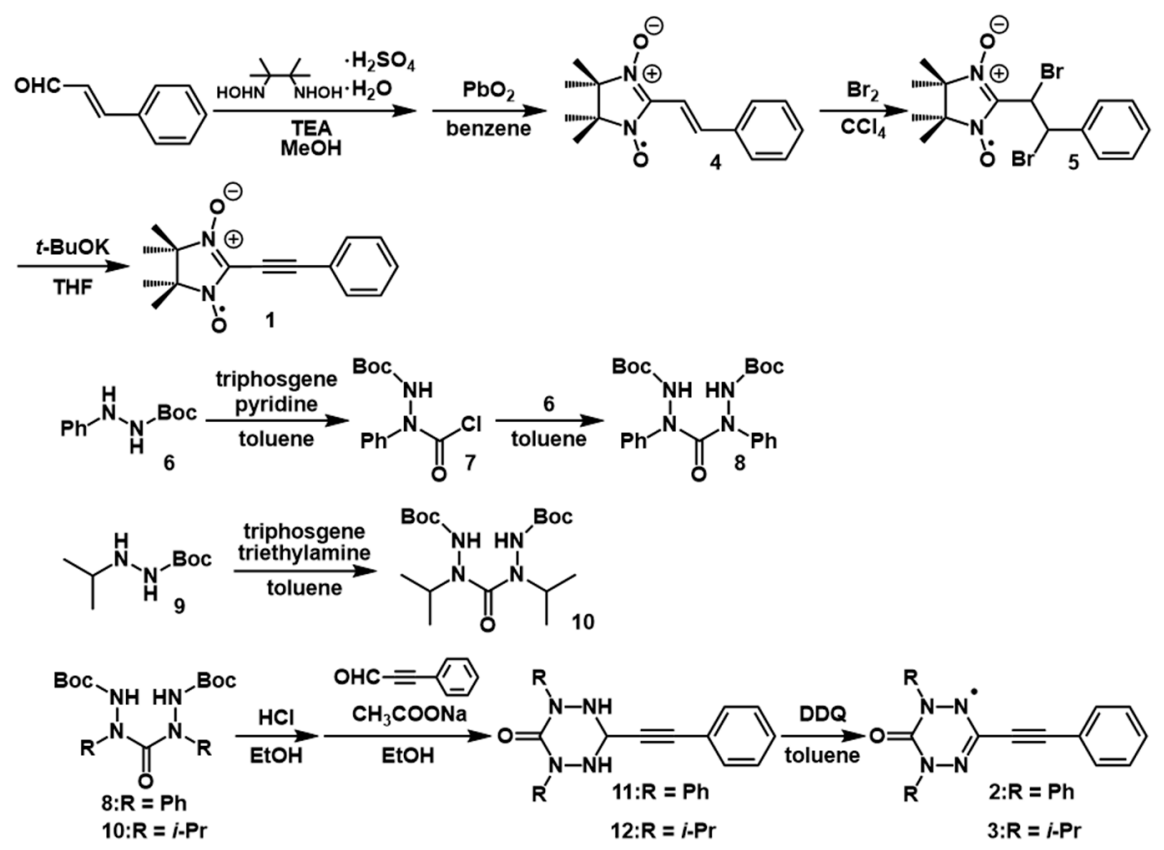

Scheme 1. Synthesis of 1, 2, and 3.

The solution electron paramagnetic resonance (EPR) spectra of these radicals exhibited typical patterns for NN and VZ derivatives (Figure S5). The hyperfine coupling constants (hfcc) and $g$ value of compounds $\mathbf{1}-\mathbf{3}$ are summarized in Table 1.

Table 1. EPR parameters of 1, 2 and 3 in toluene.

\begin{tabular}{ccc}
\hline & $\alpha_{\mathbf{N}}(\mathrm{G})$ & $g$ \\
\hline $\mathbf{1}$ & $7.32,7.35$ & 2.0062 \\
$\mathbf{2}$ & $4.62,4.64,6.39,6.40$ & 2.0033 \\
$\mathbf{3}$ & $5.29,5.61,6.52,6.56$ & 2.0031 \\
\hline
\end{tabular}




\subsection{X-ray Structural Analysis}

The single crystal of $\mathbf{1}$ was obtained by slow evaporation of the solvent (dichloromethane: $n$-hexane $=5: 3$ ) and it was a blue plate-like crystal. The X-ray structure analysis of $\mathbf{1}$ revealed that the crystal system was monoclinic and the space group was $C c$ (Table S1) [53]. Figure 1 shows an ORTEP drawing of 1 and the dihedral angle of the phenyl ring to the NN group was determined to be $77.81(12)^{\circ}$, which is a very big torsion. Three types of intermolecular close arrangements were confirmed, labeled Pair I, Pair II, and Pair III (Figure 2). In Pair I, the O atom of NN and two H atoms of the methyl group were the closest sites. On the other hand, the $\mathrm{O}$ atom of $\mathrm{NN}$ and $\mathrm{H}$ atom of the phenyl group were the closest to Pair II and Pair III, respectively.

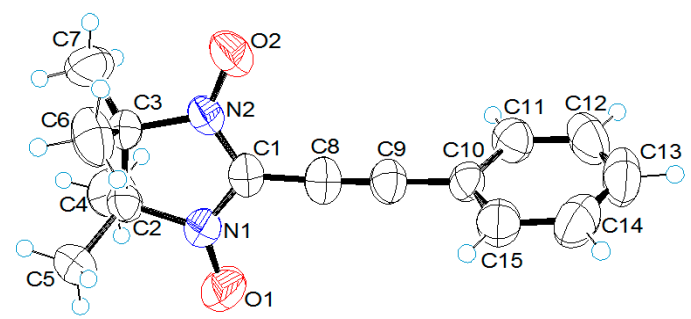

Figure 1. ORTEP drawing of $\mathbf{1}$. Thermal ellipsoids are shown as $50 \%$ probability.

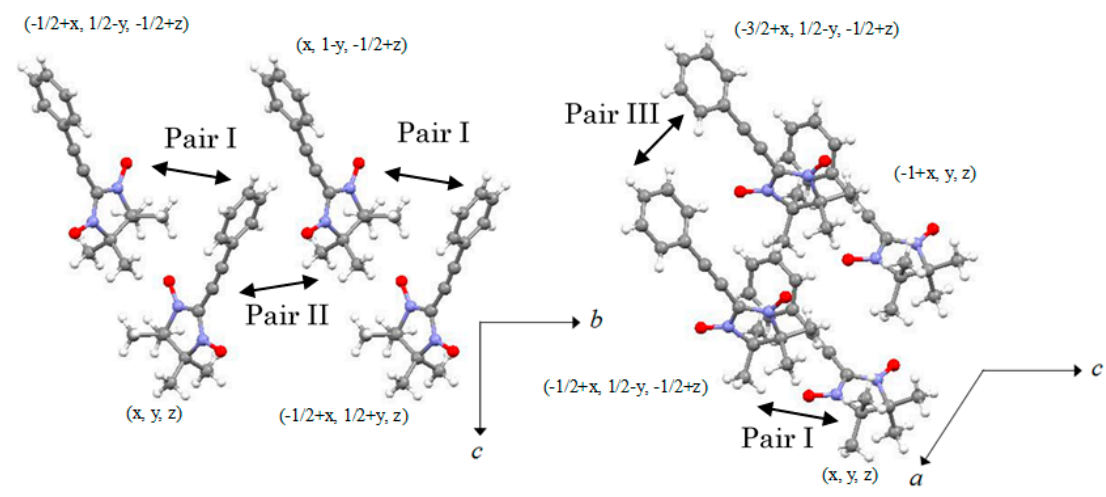

Figure 2. Crystal structure of $\mathbf{1}$.

The slow evaporation of a mixed solvent (ethyl acetate: $n$-hexane $=1: 1$ ) formed the single crystal of 2 as a dark red plate-like crystal. The crystal system and space group were triclinic and $P-1$, respectively (Table S1) [53]. Figure 3 shows the ORTEP drawing of 2 . The dihedral angle between the VZ ring and phenyl group at positions 1 and 5 were $41.68(9)^{\circ}$ and $50.08(6)^{\circ}$, respectively, but for the phenyl group at position 3 , it was $8.26(11)^{\circ} .2$ had an antiparallel stacking and two intermolecular contacts (Figure 4). The intermolecular distances of Pair IV and Pair V were 3.343(2) $\AA$ for $d_{\mathrm{N} 1-\mathrm{N} 4^{\prime}}$ and 3.710(3) $\AA$ for $d_{\mathrm{C} 15-\mathrm{C} 16^{\prime}}$.

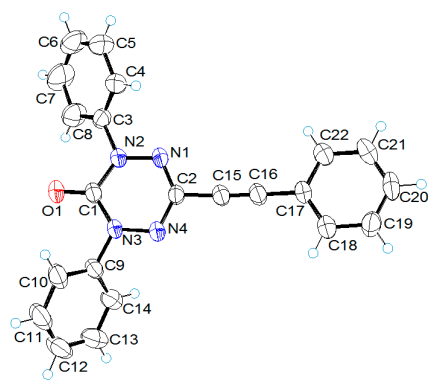

Figure 3. ORTEP drawing of 2 . Thermal ellipsoids are shown as 50\% probability. 


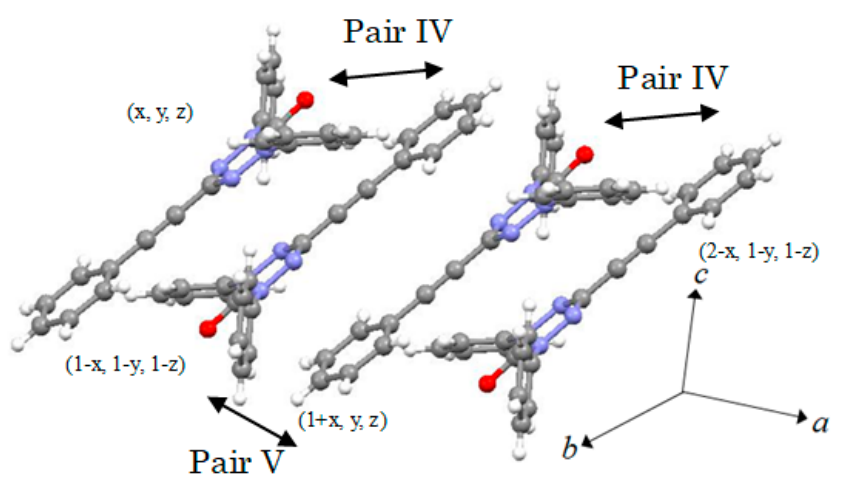

Figure 4. Crystal structure of 2.

The single crystal of 3 was obtained by slow evaporation of a mixed solvent (dichloromethane: $n$-hexane $=1: 2$ ) as orange needles. The crystal system and space group were monoclinic and $P 2_{1} / n$, respectively [53]. Details of the crystallographic data are listed in Table S1. The crystal packing of 3 was composed of three different molecules labeled A, B, and C in Figure 5. Dihedral angles between the phenyl group and $\mathrm{VZ}$ unit were $7.42(25)^{\circ}(\mathrm{A}), 3.88(25)^{\circ}(\mathrm{B})$, and $46.02(13)^{\circ}(\mathrm{C})$. There was linear stacking between the same structural molecules; A, B, and C made Pair VI, Pair VII, and Pair VIII (Figure 6), respectively. The intermolecular distances were 3.701(5) $\AA$ for $d_{\mathrm{C} 2-\mathrm{C} 11^{\prime}, 3.681(6)} \AA$ for $d_{\mathrm{C} 18-\mathrm{C} 27^{\prime}}$, and $4.171(6) \AA$ for $d_{\mathrm{C} 34-\mathrm{C} 43^{\prime}}$ in Pair VI, Pair VII, and Pair VIII, respectively.

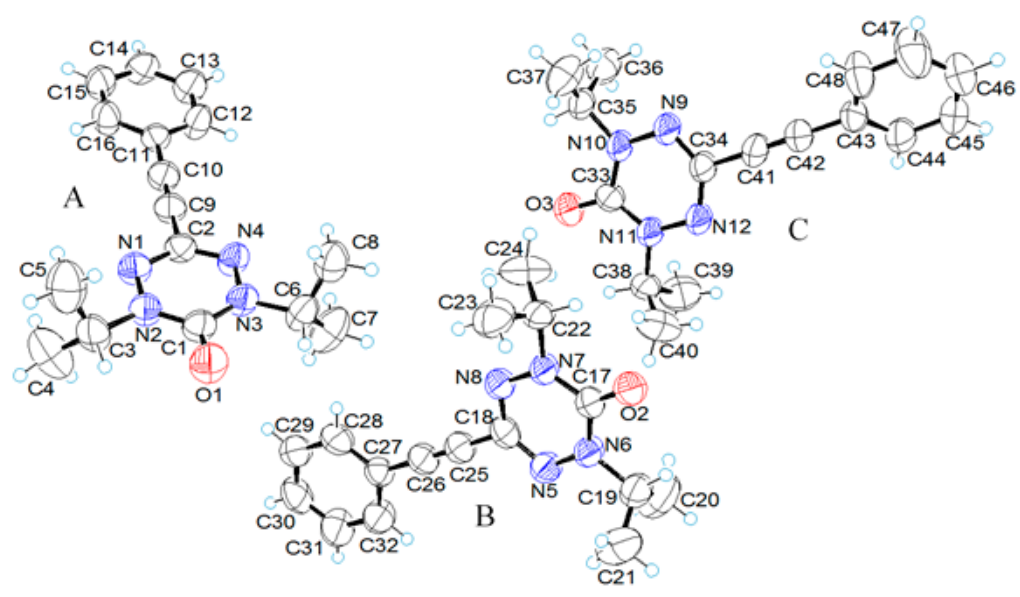

Figure 5. ORTEP drawing of 3 . Thermal ellipsoids are shown as 50\% probability.
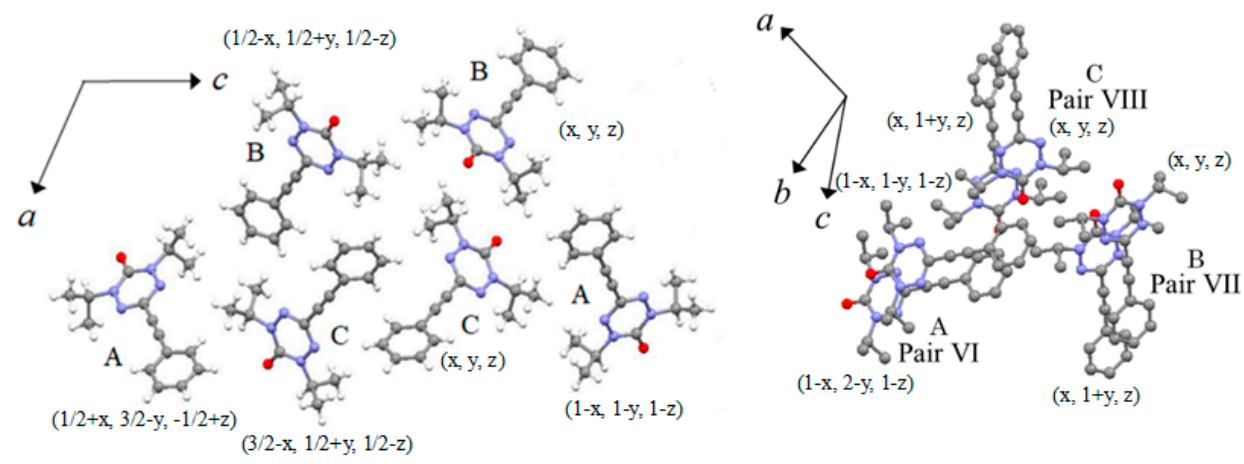

Figure 6. Crystal structure of 3. 


\subsection{Magnetic Properties}

The solid-state magnetic susceptibility measurements of $\mathbf{1}, \mathbf{2}$, and 3 were carried out by a SQUID magnetometer in the temperature region of $1.8-300 \mathrm{~K}$. The $\chi_{\mathrm{m}} T-T$ and $\chi_{\mathrm{m}}-T$ plots for 1 and 3 (Figure 7) exhibit a similar pattern. Cooling did not cause any remarkable changes in the $\chi_{\mathrm{m}} T$ values, which indicated that they were in an isolated doublet-state. The $\chi_{\mathrm{m}}{ }^{-1}-T$ plots of 1 and 3 showed that their Weiss temperatures were $-0.13 \mathrm{~K}$ and $-1.0 \mathrm{~K}$, respectively. However, the $\chi_{\mathrm{m}}$ value of 2 had a maximum at $80 \mathrm{~K}$ and the minimum at $15 \mathrm{~K}$, and the $\chi_{\mathrm{m}} T$ value decreased with cooling, meaning that the antiferromagnetic interaction was dominant. Fitting with the antiferromagnetic dimer model revealed that the magnetic interaction, $2 J / k_{\mathrm{B}}$, of 2 was $-118 \mathrm{~K}$, containing $0.5 \%$ of the isolated component.

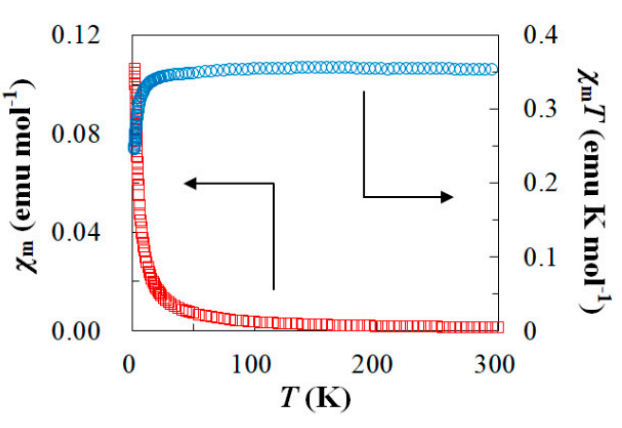

(a)

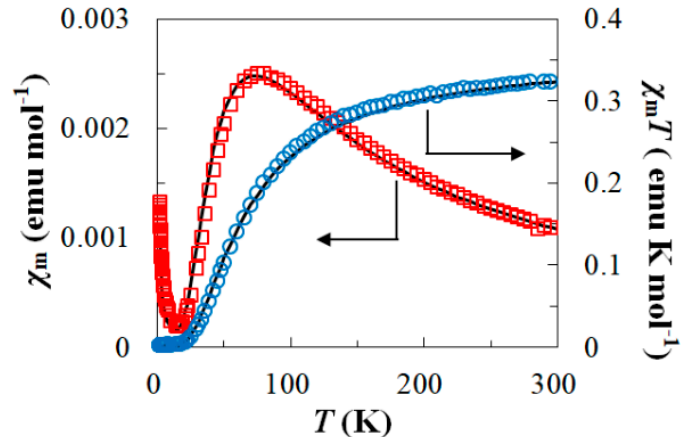

(b)

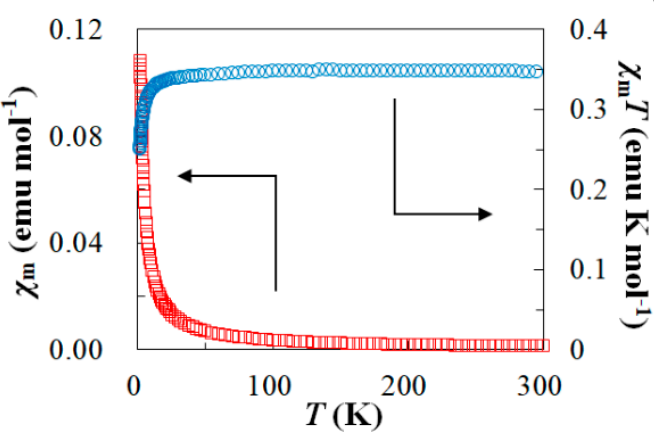

(c)

Figure 7. Temperature dependence of $\chi_{\mathrm{m}} T(\bigcirc)$ and $\chi_{\mathrm{m}}(\square)$ for $\mathbf{1}(\mathbf{a}), 2(\mathbf{b})$ and 3(c) under the applied field of 10000 Oe (1 and 2) or 5000 Oe (3) (1.8-300 K).

Antiferromagnetic dimer model equation

$$
\chi_{\mathrm{m}}=\frac{N_{\mathrm{A}} g^{2} \mu_{\mathrm{B}}^{2}}{k_{\mathrm{B}} T}\left(\frac{1}{3+\exp \left(-\frac{2 J}{k_{\mathrm{B}} T}\right)}(1-\rho)+\frac{1}{4} \rho\right)
$$

$\chi_{\mathrm{m}}$ : magnetic susceptibility; $N_{\mathrm{A}}$ : Avogadro constant; $g: g$ factor; $\mu_{\mathrm{B}}$ : Bohr magneton; $k_{\mathrm{B}}$ : Boltzmann constant; $\rho$ : isolated component.

\section{Discussion}

The magnetic interactions of the abovementioned pairs were calculated by DFT at the UB3LYP/6-31G* level, and the calculation results are substituted into Yamaguchi's equation [54] (Table 2). In 1 and 3 , the value of $J / k_{\mathrm{B}}$ for all the pairs was nearly zero; these results agreed with the SQUID measurement. In these pairs, the $C, N$, and $\mathrm{O}$ atoms of the radical ring that have a large spin density were not close to the $\mathrm{C}, \mathrm{N}$, and $\mathrm{O}$ atoms of the neighboring radical ring. However, Pair V had a low value of $J / k_{\mathrm{B}}$, and Pair IV had a large negative value that was thought to cause the 
antiferromagnetic behavior of the SQUID measurement. It was suggested that the antiferromagnetic interaction was caused by the intermolecular interaction between the N1 and N4 atoms $(x, y, z)$ that have large spin density and the $\mathrm{N}^{\prime}$ and $\mathrm{N} 4^{\prime}$ atoms of neighboring molecules $(1-x, 1-y, 1-z)$. The values of the spin density of the atoms that form the six-membered ring and phenylacetylene group of 1-3 are shown in Tables S2-S6, respectively.

Table 2. Estimation of intermolecular magnetic interactions of 1, 2, and 3.

\begin{tabular}{ccccccccc}
\hline & \multicolumn{3}{c}{$\mathbf{1}$} & \multicolumn{3}{c}{$\mathbf{2}$} & 3 \\
\cline { 2 - 9 } & Pair I & Pair II & Pair III & Pair IV & Pair V & Pair VI & Pair VII & Pair VIII \\
\hline $2 J / k_{\mathrm{B}}(\mathrm{K})$ & 0.190 & 0.190 & -0.0632 & -79.4 & -1.58 & -1.26 & -2.91 & -0.948 \\
\hline
\end{tabular}

To estimate the influence of the rotation of the ethynyl group on the extent of the spin density, the molecules that were based on the crystal structures and rotated between the phenyl group and radical ring at 15 -degree intervals $\left(0-90^{\circ}\right)$ were calculated by DFT. The sum of the spin density that was taken as an absolute value was used in the plots of Figure 8. The spin density of the radical group and the ethynyl group remained almost constant; however, that of the phenyl group decreased with rotation. This result indicated that the spin density was difficult to expand at the higher dihedral angle of ethynyl like other conjugated systems.

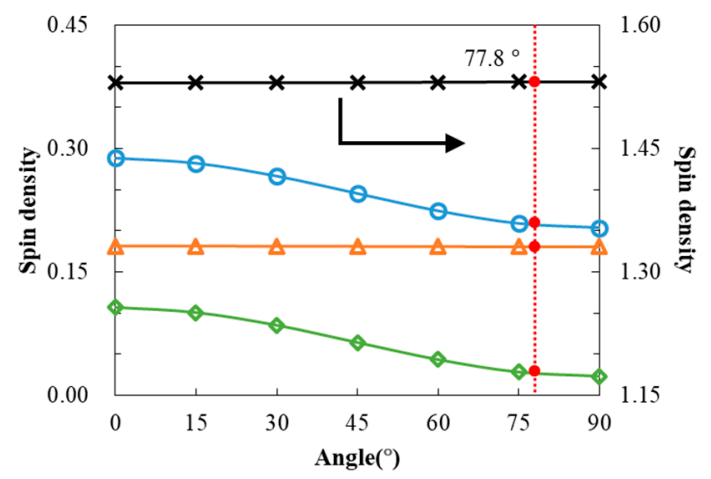

(a)

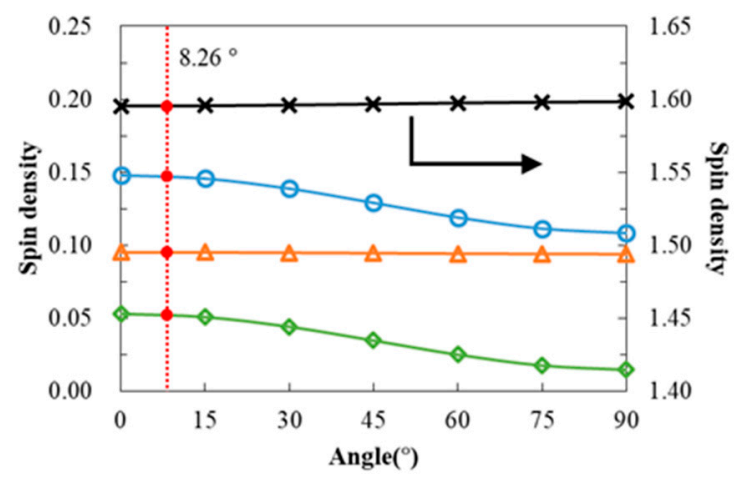

(b)

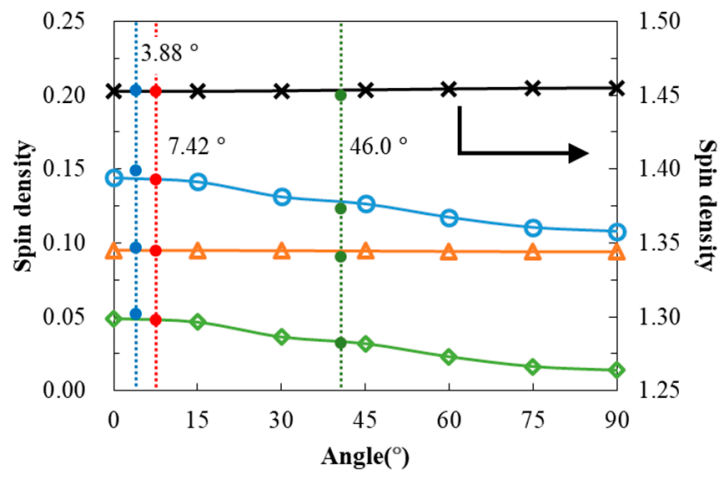

(c)

Figure 8. Correlation between dihedral angle and spin density of $\mathbf{1}(\mathbf{a}), \mathbf{2}(\mathbf{b})$ and $\mathbf{3}(\mathbf{c})$; Radical group $(\times)$, the sum of the ethynyl and phenyl $(\bigcirc)$, ethynyl $(\triangle)$, phenyl $(\diamond)$ and experimental data $(\bullet, \bullet$ and $\bullet)$. 


\section{Experimental}

Compounds 1, 4, and 5 [38], 6 [49], 9 and 10 [50], phenylpropargylaldehyde [48] were synthesized with reference to the respective papers. The details of the methods for synthesizing the other compounds are summarized in the Supplementary Materials.

The NMR spectra were measured by JEOL JNM-LA300 (Tokyo, Japan) (tetramethylsilane was used as the reference). Mass spectroscopy was carried out using a Bruker Ultraflex II (MALDI-TOF, with sinapic acid used as the matrix) (Billerica, MA, USA). The IR spectra were measured using a JASCO FT/IR-4100 (Tokyo, Japan). The crystal data were collected using a Bruker D8 Venture with Mo-K $\alpha$ radiation $(0.71073 \AA$ ). The structures were solved by the direct method using SHELXT-2013 (Göttingen, Germany) [55] and refined by $F^{2}$ full matrix least squares using SHELXL-2014 (Göttingen, Germany) [56] in the Bruker APEX-II program package. The magnetic susceptibility measurement was carried out using a Quantum Design MPMS-XL SQUID (San Diego, CA, USA) magnetometer in the temperature range of 1.8-300 K under the applied field of 10000 Oe (1 and 2) or 5000 Oe (3). The EPR spectra were recorded using a Bruker E500 spectrometer (Billerica, MA, USA) at room temperature. The EPR data were simulated by the Winsim ver. 0.96 program (Bethesda, MD, USA) [57]. The DFT calculation was carried out using the Gaussian 09 program (Wallingford, CT, USA) [58].

\section{Conclusions}

As stable organic radicals carrying an ethynyl group, the nitronyl nitroxide derivative 1 and verdazyl derivatives $\mathbf{2}$ and $\mathbf{3}$ were synthesized. X-ray crystal analysis revealed their packing structures, and 1-3 had several types of close intermolecular contacts. The magnetic susceptibility measurement revealed that 1 and 3 had an isolated doublet-state and $\mathbf{2}$ was an antiferromagnetic compound that fitted with $2 \mathrm{~J} / k_{\mathrm{B}}=-118 \mathrm{~K}$ containing $0.5 \%$ of the isolated component. DFT calculations of $\mathbf{1}, \mathbf{2}$, and 3 agreed with the results of the magnetic susceptibility measurements, and indicated that the spin density of the phenyl group decreased due to the free rotation of the acetylene unit.

Supplementary Materials: The Supplementary Materials are available online: supplementary materials contain synthetic procedure, EPR spectra, crystallographic parameter, and distributions of SOMO and spin density.

Acknowledgments: This work was partly supported by the MEXT Supported Program for the Strategic Research Foundation at Private Universities, 2012-2016.

Author Contributions: Shogo Miyashiro wrote the draft. He and Tomoaki Ishii contributed to the synthesis of the radical derivatives and X-ray diffraction analyses and physicochemical characterizations. Youhei Miura contributed support to syntheses and characterizations. Naoki Yoshioka contributed to the conception and revision of the submitted manuscript.

Conflicts of Interest: The authors declare no conflict of interest.

\section{References}

1. Lahti, P.M. (Ed.) Magnetic Properties of Organic Materials; Marcel Dekker: New York, NY, USA, 1999; ISBN 9780824719760.

2. Miller, J.S.; Drillon, M. (Eds.) Magnetism: Molecules to Materials; Wiley-VCH: Weinheim, Germany, 2005; Volume I-V. [CrossRef]

3. Hicks, R.G. (Ed.) Stable Radicals: Fundamentals and Applied Aspects of Odd-Electron Compounds; Wiley: Chichester, UK, 2010; ISBN 978-0-470-77083-2.

4. Chatgilialoglu, C.; Studer, A. (Eds.) Encyclopedia of Radicals in Chemistry, Biology and Materials; Wiley: Hoboken, NJ, USA, 2012.

5. Koivisto, B.D.; Hicks, R.G. The magnetochemistry of verdazyl radical-based materials. Coord. Chem. Rev. 2005, 249, 2612-2630. [CrossRef]

6. Vostrikova, K.E. High-spin molecules based on metal complexes of organic free radicals. Coord. Chem. Rev. 2008, 252, 1409-1419. [CrossRef]

7. Retera, I.; Veciana, J. Playing with organic radicals as building blocks for functional molecular materials. Chem. Soc. Rev. 2012, 41, 303-349. [CrossRef] [PubMed] 
8. Lipunova, G.N.; Fedorchenko, T.G.; Chupakhin, O.N. Verdazyls: Synthesis, properties, application. Russ. Chem. Rev. 2013, 82, 701-734. [CrossRef]

9. Mukai, K. Anomalous magnetic properties of stable crystalline phenoxyl radicals. Bull. Chem. Soc. Jpn. 1969, 42, 40-46. [CrossRef]

10. Chouteau, G.; Veyret-Jeandey, C. Metamagnetism in tanol suberate. J. Phys. Paris 1981, 42, 1441-1444. [CrossRef]

11. Sugawara, T.; Murata, S.; Kimura, K.; Iwamura, H.; Sugawara, Y.; Iwasaki, H. Design of molecular assembly of diphenylcarbenes having ferromagnetic intermolecular interactions. J. Am. Chem. Soc. 1985, 107, 5293-5294. [CrossRef]

12. Awaga, K.; Sugano, T.; Kinoshita, M. Ferromagnetic intermolecular interactions in a series of organic mixed crystals of galvinoxyl radical and its precursory closed shell compound. J. Chem. Phys. 1986, 85, 2211-2218. [CrossRef]

13. Tamura, M.; Nakazawa, Y.; Shiomi, D.; Nozawa, K.; Hosokoshi, Y.; Ishikawa, M.; Takahashi, M.; Kinoshita, M. Bulk ferromagnetism in the $\beta$-phase crystal of the p-nitrophenyl nitronyl nitroxide radical. Chem. Phys. Lett. 1991, 186, 401-404. [CrossRef]

14. Chiarelli, R.; Novak, M.A.; Rassat, A.; Tholence, J.L. A ferromagnetic transition at $1.48 \mathrm{~K}$ in an organic nitroxide. Nature 1993, 363, 147-149. [CrossRef]

15. Lanfranc de Panthou, F.; Luneau, D.; Laugier, J.; Rey, P. Crystal structures and magnetic properties of a nitronyl nitroxide and of its imino analog. Crystal packing and spin distribution dependence of ferromagnetic intermolecular interactions. J. Am. Chem. Soc. 1993, 115, 9095-9100. [CrossRef]

16. Pei, Y.; Kahn, O.; Aebersold, M.A.; Ouahab, L.; Le Berre, F.; Pardi, L.; Jean Louis, T. Synthesis, Crystal Structure, Magnetic Properties, and Spin Densities of a Triazole-Nitronyl Nitroxide Radical. Adv. Mater. 1994, 6, 681-683. [CrossRef]

17. Cirujeda, J.; Mas, M.; Molins, E.; Lanfranc de Panthou, F.; Laugier, J.; Park, J.G.; Paulsen, C.; Rey, P.; Rovira, C.; Veciana, J. Control of the structural dimensionality in hydrogen-bonded self-assemblies of open-shell molecules. Extension of intermolecular ferromagnetic interactions in $\alpha$-phenyl nitronyl nitroxide radicals into three dimensions. J. Chem. Soc. Chem. Commun. 1995, 709-710. [CrossRef]

18. Lang, A.; Pei, Y.; Ouahab, L.; Kahn, O. Synthesis, crystal structure, and magnetic properties of 5-methyl-1,2,4-triazole-nitronyl nitroxide: A one-dimensional compound with unusually large ferromagnetic intermolecular interactions. Adv. Mater. 1996, 8, 60-62. [CrossRef]

19. Matsushita, M.M.; Izuoka, A.; Sugawara, T.; Kobayashi, T.; Wada, N.; Takeda, N.; Ishikawa, M. Hydrogen-Bonded Organic Ferromagnet. J. Am. Chem. Soc. 1997, 119, 4369-4379. [CrossRef]

20. Yoshioka, N.; Irisawa, M.; Mochizuki, Y.; Kato, T.; Inoue, H.; Ohba, S. Unusually Large Magnetic Interactions Observed in Hydrogen-Bonded Nitronyl Nitroxides. Chem. Lett. 1997, 26, 251-257. [CrossRef]

21. Nagashima, H.; Hashimoto, N.; Inoue, H.; Yoshioka, N. Coexistence of an antiferromagnetically coupled dimer and isolated paramagnetic spin in 4-azaindol-2-yl nitronyl nitroxide crystal. New J. Chem. 2003, 27, 805-810. [CrossRef]

22. Nagashima, H.; Inoue, H.; Yoshioka, N. An ideal one-dimensional antiferromagnetic spin system observed in hydrogen-bonded naphth[2,3- $d$ ]imidazol-2-yl nitronyl nitroxide crystal: The role of the hydrogen bond. J. Phys. Chem. B 2004, 108, 6144-6151. [CrossRef] [PubMed]

23. Nagashima, H.; Fujita, S.Y.; Inoue, H.; Yoshioka, N. Metamagnetic Behavior Observed in Purely Organic 5-Azaindol-2-yl Nitronyl Nitroxide Brick-Wall Architecture. Cryst. Growth Des. 2004, 4, 19-21. [CrossRef]

24. Yao, M.; Asakura, S.; Abe, M.; Inoue, H.; Yoshioka, N. Formation of a One-Dimensional Stacking Structure of $\pi$-Conjugated Nitroxyl Radical Bearing a 1,2,5-Thiadiazole Ring and Its Magnetic Property. Cryst. Growth Des. 2005, 5, 413-417. [CrossRef]

25. Murata, H.; Mague, J.T.; Aboaku, S.; Yoshioka, N.; Lahti, P.M. An Organic Radical Solid Solution with Strong Ferromagnetic Exchange. Chem. Mater. 2007, 19, 4111-4113. [CrossRef]

26. Murata, H.; Miyazaki, Y.; Inaba, A.; Paduan-Filho, A.; Bindilatti, V.; Oliveira, N.F., Jr.; Delen, Z.; Lahti, P.M. 2-(4,5,6,7-Tetrafluorobenzimidazol-2-yl)-4,4,5,5-tetramethyl-4,5-dihydro-1-H-imidazole-3-oxide-1-oxyl, A Hydrogen-Bonded Organic Quasi-1D Ferromagnet. J. Am. Chem. Soc. 2008, 130, 186-194. [CrossRef] [PubMed]

27. Takahashi, Y.; Miura, Y.; Yoshioka, N. Synthesis and properties of the 3-tert-butyl-7-trifluoromethyl1,4-dihydro-1-phenyl-1,2,4-benzotriazin-4-yl radical. New J. Chem. 2015, 39, 4783-4789. [CrossRef] 
28. Azuma, N.; Yamauchi, J.; Mukai, K.; Ohya, H.N.; Deguchi, Y. The Magnetic Properties of Verdazyl Free Radicals. III. The Anomalous Magnetic Behavior of Symmetrical Triphenylverdazyl. Bull. Chem. Soc. Jpn. 1973, 46, 2728-2734. [CrossRef]

29. Allemand, P.M.; Srdanov, G.; Fred, F. Molecular engineering in the design of short-range ferromagnetic exchange in organic solids: The 1,3,5-triphenylverdazyl system. J. Am. Chem. Soc. 1990, 112, 9391-9392. [CrossRef]

30. Mito, M.; Takeda, K.; Mukai, K.; Azuma, N.; Gleiter, M.R.; Krieger, C.; Neugebauer, F.A. Magnetic Properties and Crystal Structures of 1,5-Diphenylverdazyls with Electron Acceptor Groups in the 3-Position. J. Phys. Chem. B 1997, 101, 9517-9524. [CrossRef]

31. Hicks, R.G.; Lemaire, M.T.; Oehrstroem, L.; Richardson, J.F.; Thompson, L.K.; Xu, Z. Strong Supramolecular-Based Magnetic Exchange in $\pi$-Stacked Radicals. Structure and Magnetism of a Hydrogen-Bonded Verdazyl Radical: Hydroquinone Molecular Solid. J. Am. Chem. Soc. 2001, 123, 7154-7159. [CrossRef] [PubMed]

32. Mukai, K.; Matsubara, M.; Hisatou, H.; Hosokoshi, Y.; Inoue, K.; Azuma, N. Anomalous Magnetic Behavior in Three Kinds of 3-(Aryl-substituted)-1,5-diphenylverdazyl Radical Crystals ( $p$-FPDV, $p$-PyDV and $m$-PyDV) Induced by Frustrated Spin Interaction. J. Phys. Chem. B 2002, 106, 8632-8638. [CrossRef]

33. Merhi, A.; Roisnel, T.; Rigaut, S.; Train, C.; Norel, L. Ferromagnetic intermolecular exchange interaction in ethynyl-verdazyl radical crystals. Cryst. Eng. Comm. 2014, 16, 9783-9787. [CrossRef]

34. Eusterwiemann, S.; Dresselhaus, T.; Doerenkamp, C.; Janka, O.; Niehaus, O.; Massolle, A.; Daniliuc, C.G.; Eckert, H.; Poettgen, R.; Neugebauer, J.; et al. Cooperative Magnetism in Crystalline N-Aryl-Substituted Verdazyl Radicals: First-Principles Predictions and Experimental Results. Chem. Eur. J. 2017, 23, 6069-6082. [CrossRef] [PubMed]

35. Eusterwiemann, S.; Doerenkamp, C.; Dresselhaus, T.; Janka, O.; de Oliveira, M., Jr.; Daniliuc, C.G.; Eckert, H.; Neugebauer, J.; Poettgen, R.; Studer, A. Strong intermolecular antiferromagnetic verdazyl-verdazyl coupling in the solid state. Phys. Chem. Chem. Phys. 2017, 19, 15681-15685. [CrossRef] [PubMed]

36. Ducharme, Y.; Wuest, J.D. Use of Hydrogen Bonds to Control Molecular Aggregation. Extensive, Self-complementary Arrays of Donors and Acceptors. J. Org. Chem. 1988, 53, 5787-5789. [CrossRef]

37. Simard, M.; Su, D.; Wuest, J.D. Use of Hydrogen Bonds to Control Molecular Aggregation. Self-Assembly of Three-Dimensional Networks with Large Chambers. J. Am. Chem. Soc. 1991, 113, 4696-4698. [CrossRef]

38. Ullman, E.F.; Osiecki, J.H.; Boocock, D.G.B.; Darcy, R. Stable free radicals. X. Nitronyl nitroxide monoradicals and biradicals as possible small molecule spin labels. J. Am. Chem. Soc. 1972, 94, 7049-7059. [CrossRef]

39. Dulog, L.; Kim, J.S. Stable free radical paramagnetic monomers containing aminoxylamine oxide moieties. An intermediate step toward organic ferromagnetic polyradicals. Makromol. Chem. 1989, 190, 2604-2614. [CrossRef]

40. Tretyakov, E.V.; Romanenko, G.V.; Podoplelov, A.; Ovcharenko, V. Synthesis of alkynyl-substituted nitronyl nitroxides through an organosilicon derivative. Eur. J. Org. Chem. 2006, 2695-2702. [CrossRef]

41. Tretyakov, E.V.; Romanenko, G.V.; Ovcharenko, V.I. Alkynyl-substituted nitronyl nitroxide. Russ. Chem. Bull. 2006, 55, 591-592. [CrossRef]

42. Tretyakov, E.V.; Tolstikov, S.E.; Romanenko, G.V.; Bogomyakov, A.S.; Stass, D.V.; Kadirov, M.K.; Holin, K.V.; Sinyashin, O.G.; Ovcharenko, V.I. Synthesis, structure, and magnetic properties of 2,2'-(buta-1,3-diyne-1,4-diyl)bis(4,4,5,5-tetramethyl-4,5-dihydro-1H-imidazole 3-oxide 1-oxyl). Polyhedron 2011, 30, 3232-3237. [CrossRef]

43. Ko, K.C.; Cho, D.; Lee, J.Y. Systematic Approach to Design Organic Magnetic Molecules: Strongly Coupled Diradicals with Ethylene Coupler. J. Phys. Chem. A 2012, 116, 6837-6844. [CrossRef] [PubMed]

44. Sarbadhikary, P.; Shil, S.; Panda, A.; Misra, A. A Perspective on Designing Chiral Organic Magnetic Molecules with Unusual Behavior in Magnetic Exchange Coupling. J. Org. Chem. 2016, 81, 5623-5630. [CrossRef] [PubMed]

45. Steenbock, T.; Shultz, D.A.; Kirk, M.L.; Herrmann, C. Influence of Radical Bridges on Electron Spin Coupling. J. Phys. Chem. A 2017, 121, 216-225. [CrossRef] [PubMed]

46. Neugebauer, F.A.; Fischer, H.; Krieger, C. Verdazyls. Part 33. EPR and ENDOR studies of 6-oxoand 6-thioxoverdazyls. X-Ray molecular structure of 1,3,5-triphenyl-6-oxoverdazyl and 3-tert-butyl1,5-diphenyl-6-thioxoverdazyl. J. Chem. Soc. Perkin Trans. 1993, 2, 535-544. [CrossRef] 
47. Milcent, R.; Barbier, G.; Capelle, S.; Catteau, J.P. New general synthesis of tetrahydro-1,2,4,5tetrazin-3(2H)-one derivatives and stable 3,4-dihydro-3-oxo-1,2,4,5-tetrazin-1(2H)-yl radical derivatives. J. Heterocycl. Chem. 1994, 31, 319-324. [CrossRef]

48. Paré, E.C.; Brook, D.J.R.; Brieger, A.; Badik, M.; Schinke, M. Synthesis of 1,5-diisopropyl substituted 6-oxoverdazyls. Org. Biomol. Chem. 2005, 3, 4258-4261. [CrossRef] [PubMed]

49. Tayama, E.; Kobayashi, Y.; Toma, Y. Diaza [1,4] Wittig-type rearrangement of $N$-allylicN-Boc-hydrazines into $\gamma$-amino-N-Boc-enamines. Chem. Commun. 2016, 52, 10570-10573. [CrossRef] [PubMed]

50. Melendez, R.E.; Lubell, W.D. Aza-Amino Acid Scan for Rapid Identification of Secondary Structure Based on the Application of N-Boc-Aza ${ }^{1}$-Dipeptides in Peptide Synthesis. J. Am. Chem. Soc. 2004, 126, 6759-6764. [CrossRef] [PubMed]

51. Kuroda, H.; Hanaki, E.; Izawa, H.; Kano, M.; Itahashi, H. A convenient method for the preparation of $\alpha$-vinylfurans by phosphine-initiated reactions of various substituted enynes bearing a carbonyl group with aldehydes. Tetrahedron 2004, 60, 1913-1920. [CrossRef]

52. Masuda, Y.; Kuratsu, M.; Suzuki, S.; Kozaki, M.; Shiomi, D.; Sato, K.; Takui, T.; Okada, K. Preparation and magnetic properties of verdazyl-substituted dihydrophenazine radical cation tetrachloroferrate salts. Polyhedron 2009, 28, 1950-1954. [CrossRef]

53. CCDC 1587567, 1587568 and 1587569 for 1, 2, and 3, Respectively, Contain the Supplementary Crystallographic Data for This Paper. Available online: http:/ / www.ccdc.cam.ac.uk/conts/retrieving.html (11 November 2017).

54. Yamaguchi, K.; Fukui, H.; Fueno, T. Molecular orbital (MO) theory for magnetically interacting organic compounds ab-initio $\mathrm{MO}$ calculations of the effective exchange integrals for cyclophane-type carbene dimers. Chem. Lett. 1986, 625-628. [CrossRef]

55. Sheldrick, G.M. SHELXT-Integrated space-group and crystal-structure determination. Acta Crystallogr. Sect. A 2015, 71, 3-8. [CrossRef] [PubMed]

56. Sheldrick, G.M. Crystal structure refinement with SHELXL. Acta Crystallogr. Sect. C 2015, 71, 3-8. [CrossRef] [PubMed]

57. O’Brien, D.A.; Duling, D.R.; Fann, Y.C. Winsim v.0.96, EPR Spectral Simulation for MS-Windows; Public EPR Software Tools; NIEHS: Bethesda, MD, USA.

58. Frisch, M.J.; Trucks, G.W.; Schlegel, H.B.; Scuseria, G.E.; Robb, M.A.; Cheeseman, J.R.; Scalmani, G.; Barone, V.; Mennucci, B.; Petersson, G.A.; et al. Gaussian 09 (Revision D.01); Gaussian, Inc.: Wallingford, CT, USA, 2013.

Sample Availability: Samples of the compounds 1, 2 and 3 are available from the authors.

(C) 2018 by the authors. Licensee MDPI, Basel, Switzerland. This article is an open access article distributed under the terms and conditions of the Creative Commons Attribution (CC BY) license (http://creativecommons.org/licenses/by/4.0/). 